\title{
Antiviral activity of mitoxantrone dihydrochloride against human herpes simplex virus mediated by suppression of the viral immediate early genes
}

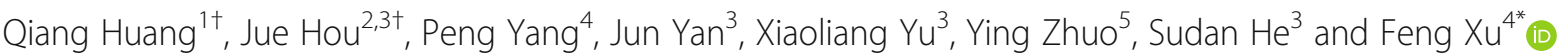

\begin{abstract}
Background: HSV-1 is a common pathogen that infects $50-90 \%$ of the human population worldwide. HSV-1 causes numerous infection-related diseases, some of which are severely life-threatening. There are antiviral medications with activity against HSV-1. However, with the emergence of drug-resistant mutant strains of HSV-1, there is an urgent need to develop new effective anti-HSV-1 agents.

Methods: Therefore, we screened a chemical library of approximately 1500 compounds to identify inhibitors of HSV-1-induced toxicity for further drug development. Moreover, we performed several experiments, including western blot analysis, Q-PCR analysis and luciferase activity assay, to explore the antiviral mechanism of the candidates.

Results: Here, we identified a small molecule, mitoxantrone dihydrochloride, with potency against HSV-1-induced toxicity. Furthermore, the viral titers and expression levels of HSV-1 viral proteins were potently reduced by the presence of MD in many cell lines. Using Q-PCR analysis, we found that MD efficiently reduced the transcription of viral genes that are essential for DNA synthesis, namely, UL5, UL9, UL29, UL30, UL42 and UL52. Notably, MD also significantly inhibited the transcription of the immediate early genes ICPO, ICP22, ICP27 and ICP47, all of which are required for the expression of early and late viral gene products. Using immunofluorescence and western blot analysis, we found that the antiviral effect of MD was independent of the activation of the NF-KB and MAPK pathways. Furthermore, we found that the reduction in the transcription of viral immediate early genes was not related to the promoter activities of ICPO.
\end{abstract}

Conclusions: Therefore, the identification of compound MD as an inhibitor of toxicity induced by HSV-1 highlights its potential use in the development of novel anti-HSV-1 drugs.

Keywords: Herpes simplex virus, Anti-HSV drugs, Mitoxantrone dihydrochloride

\section{Background}

Herpes simplex virus-1 (henceforth HSV-1) is a doublestranded DNA pathogen that possesses a large genome of approximately $150 \mathrm{k}$ nucleotides [1]. HSV-1 is recognized as one of the most common human pathogens infecting $50-90 \%$ of the population [2]. After infection,

\footnotetext{
* Correspondence: sz_xf@suda.edu.cn

${ }^{\dagger}$ Qiang Huang and Jue Hou contributed equally to this work

${ }^{4}$ Department of emergency medicine, First Affiliated Hospital, Soochow

University, 1 Shizi Rd, Suzhou, China

Full list of author information is available at the end of the article
}

HSV-1 is dormant in sensory neurons and persists for the lifetime of the host $[3,4]$. When the immune state of the host is compromised, the virus can be reactivated by the proper stimulus. Although HSV-1 mainly causes innocuous diseases, such as labialis, pharyngitis and keratitis, it can also result in serious life-threatening diseases, including encephalitis [5-9].

Mature HSV-1 contains a large DNA genome core enveloped by a protein capsid. The middle layer is referred to as tegument, which is composed of viral proteins and mRNA. The outer layer is surrounded by the

(c) The Author(s). 2019 Open Access This article is distributed under the terms of the Creative Commons Attribution 4.0 International License (http://creativecommons.org/licenses/by/4.0/), which permits unrestricted use, distribution, and reproduction in any medium, provided you give appropriate credit to the original author(s) and the source, provide a link to the Creative Commons license, and indicate if changes were made. The Creative Commons Public Domain Dedication waiver (http://creativecommons.org/publicdomain/zero/1.0/) applies to the data made available in this article, unless otherwise stated. 
glycoproteins $\mathrm{gB}, \mathrm{gC}$ and $\mathrm{gD}$, all of which are necessary for viral entry $[10,11]$. Once the HSV-1 virus enters the cytoplasm of the infected cell, its genome is released into the cell nucleus and encodes several gene products that enable viral replication [12, 13]. Viral gene expression is strictly regulated in a cascade fashion. Immediate early genes, early genes and late genes are expressed successively $[14,15]$. The immediate early genes include ICPO, ICP4, $I C P 22$, ICP27 and ICP47, whose products are required to initiate and regulate the efficient expression of early genes and late genes [16, 17]. For example, ICP0 mediates the degradation of several cellular proteins and induces the conjugation of ubiquitin. Mutation of ICP4 or ICP27 significantly blocked the expression of early and late viral genes [18]. Regulated by the immediate early genes, early genes are expressed approximately $2-8 \mathrm{~h}$ after infection. Most early genes are involved in viral replication. As the infection progresses the late genes begin to be expressed, and the products of late genes are structural proteins whose expression also depends on immediate early genes. Some HSV-1 viral proteins are known to be necessary for viral DNA synthesis and include proteins encoded by the $U L 5$, UL8, UL29, UL30, UL42 and UL52 genes [19-21]. For example, UL9 helps to unwind the DNA strain by flanking the origins of DNA replication. UL30 and UL42 are two subunits of the DNA polymerase, so losing one of these proteins impedes the elongation of viral DNA chains.

There is a number of available antiviral medications with activity against HSV-1. As a nucleoside analogue, acyclovir is commonly used for the treatment of HSV-1 infection. Because its structure is similar to that of a nucleoside, acyclovir serves as a substrate for the viral DNA polymerase and terminates the extension of the viral DNA to inhibit the proliferation of the HSV-1 virus $[22,23]$. Peciclovir and foscarnet can also hinder the elongation of HSV DNA by similar mechanisms of action as acyclovir [24]. However, with the increasing drug resistance of HSV-1 to acyclovir, research and development of new effective anti-HSV-1 agents is becoming increasingly important. It has been reported that the small molecular compound mitoxantrone dihydrochloride (henceforth MD) is a topoisomerase II inhibitor that shows promising efficacy in clinical trials targeting lymphomas, breast cancer, and prostate cancer [25-27]. In the current study, using a compound library screen, we found that MD effectively blocked not only HSV-1induced toxicity but also viral titers in multiple cell lines. MD also showed a potent effect on the expression of essential HSV-1 genes without activating the NF- $\kappa B$ and MAPK pathways or the ICPO promotor.

\section{Results}

Screening of small molecular inhibitors against HSV-1

In our previous study, we screened the LOPAC smallscale library to identify small molecules that can inhibit HSV-1-induced toxicity [28] and identified MD as a potential inhibitor of human herpes simples virus. MD has been reported as a topoisomerase II inhibitor. It has been used as an approved chemotherapy drug to treat lymphoma and prostate cancer in consideration of its antitumour activity. Since its effect on HSV-1 was unknown, we further tested the antiviral effect of MD on HSV-1. L929 cells were treated with various concentrations of MD for $1 \mathrm{~h}$ prior to HSV-1 infection. As shown in Fig. 1b, we found that HSV-1-induced cell death was inhibited significantly in a dose-dependent manner with an estimated IC:50 value of $1.21 \mu \mathrm{M}$. MD treatment with an estimated CC:50 value of $11.6 \mu \mathrm{M}$ completely suppressed HSV-1-induced toxicity at $3.13 \mu \mathrm{M}$ and had no obvious cytotoxicity to cells under this concentration (Fig. 1b and e). We further estimated whether the HSV1 titers were affected by the present of MD by plaque forming assay. The results showed that the viral titers were significantly suppressed by MD in HeLa cells $(\mathrm{t}=7.56, P<0.005)$ and L929 cells $(\mathrm{t}=10.02, P<0.005)$ (Fig. 1c and d). Moreover, the HeLa cells were infected with GFP-labelled HSV-1 to observe the efficacy more directly. We found that the GFP-labelled HSV-1 virus was significantly inhibited by MD compared with the DMSO control (Fig. 1f). Thus, these data show that MD robustly inhibits HSV-1-induced toxicity and viral replication.

\section{MD reduces the expression levels of HSV-1 proteins in both human and mouse cells}

HSV-1 glycoproteins including $\mathrm{gB}, \mathrm{gD}, \mathrm{gH}$ and $\mathrm{gL}$ are required for HSV-1 entry and cell fusion [10, 11]. ICP6 is a HSV-1 ribonucleotide large subunit that is critical for the synthesis of deoxyribonucleotide [29]. We then investigated whether MD suppressed the expression levels of HSV-1 proteins. In this study, the results of western blot analysis showed that the expression levels of gB and ICP6 were significantly suppressed in a dosedependent manner in both the mouse cell line (Fig. 2a and b) and the human cell line (Fig. $2 \mathrm{c}$ and d).

\section{MD shows antiviral efficacy even after HSV-1 entry}

Viral infection is a complex procedure consisting of entry into host cells, replication and transcription of the viral genome, viral protein synthesis, viral assembly and release [10]. Antiviral medications acting at any step of these processes will block viral infection. To investigate whether MD inhibited the expression levels of viral proteins even after HSV-1 entry, we washed cells with PBS at the indicated time points after HSV-1 infection at which HSV-1 had completed entry (Fig. 3a). Then, the 


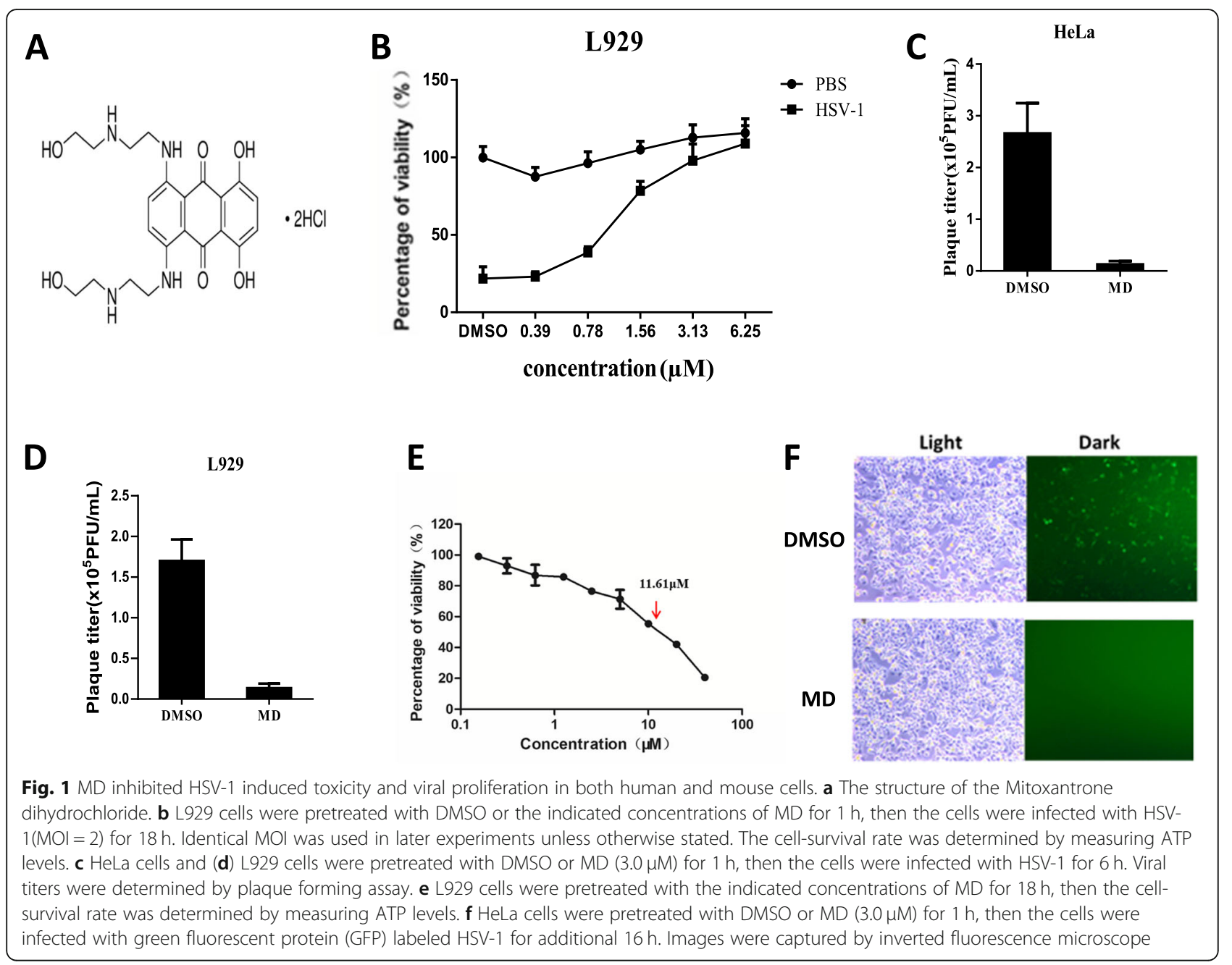

cells were cultured with fresh medium supplemented with MD for an additional $18 \mathrm{~h}$. We found that MD inhibited HSV-1-induced toxicity even after HSV-1 cell entry. (Fig. 3b). However, the later the MD was added, the worse the antiviral efficacy. MD consistently inhibited the expression of viral proteins in both human and mouse cells even after HSV-1 entered cells (Fig. 3c and d). Viral titers were also reduced in HSV-1-infected cells by post-treatment with $\mathrm{MD}(\mathrm{t}=7.76, P<0.005)$ (Fig. 3e). Overall, MD likely exhibits antiviral efficacy by suppressing the expression levels of HSV-1 proteins rather than blocking entry of virus into host cells.

\section{MD suppresses the transcription of viral genes}

Given that MD inhibited viral toxicity and suppressed the expression levels of viral proteins, we further confirmed whether the transcription levels of viral genes were also affected by MD. To examine the effects of MD on HSV-1 gene expression, total RNA was extracted from the treated cells, and Q-PCR was performed using specific primers as described in the Methods. The transcription levels of the ICP6 and GB genes were reduced by MD (Fig. 4a). This result was consistent with the observation of the protein levels by western blot (Fig. 2). HSV-1 genes such as UL5, UL8, UL9, UL42 and UL52 are required for viral DNA replication. We found that the transcription levels of these genes were also inhibited by MD (Fig. 4b). Remarkably, MD also reduced the transcription levels of the immediate early genes $I C P O$, $I C P 22$, ICP27, and ICP47, all of which are required for the expression of early and late viral gene products (Fig. 4c). These results suggest that MD inhibits HSV-1 replication by suppressing the expression of immediate early genes.

Having shown that MD suppressed the transcription of immediate early genes, we sought to characterize whether MD affects the promoter activity of immediate early genes. We generated a pGL4.17-based luciferase construct containing the ICP0 promoter sequence. Using a luciferase reporter assay, we found that MD had no 

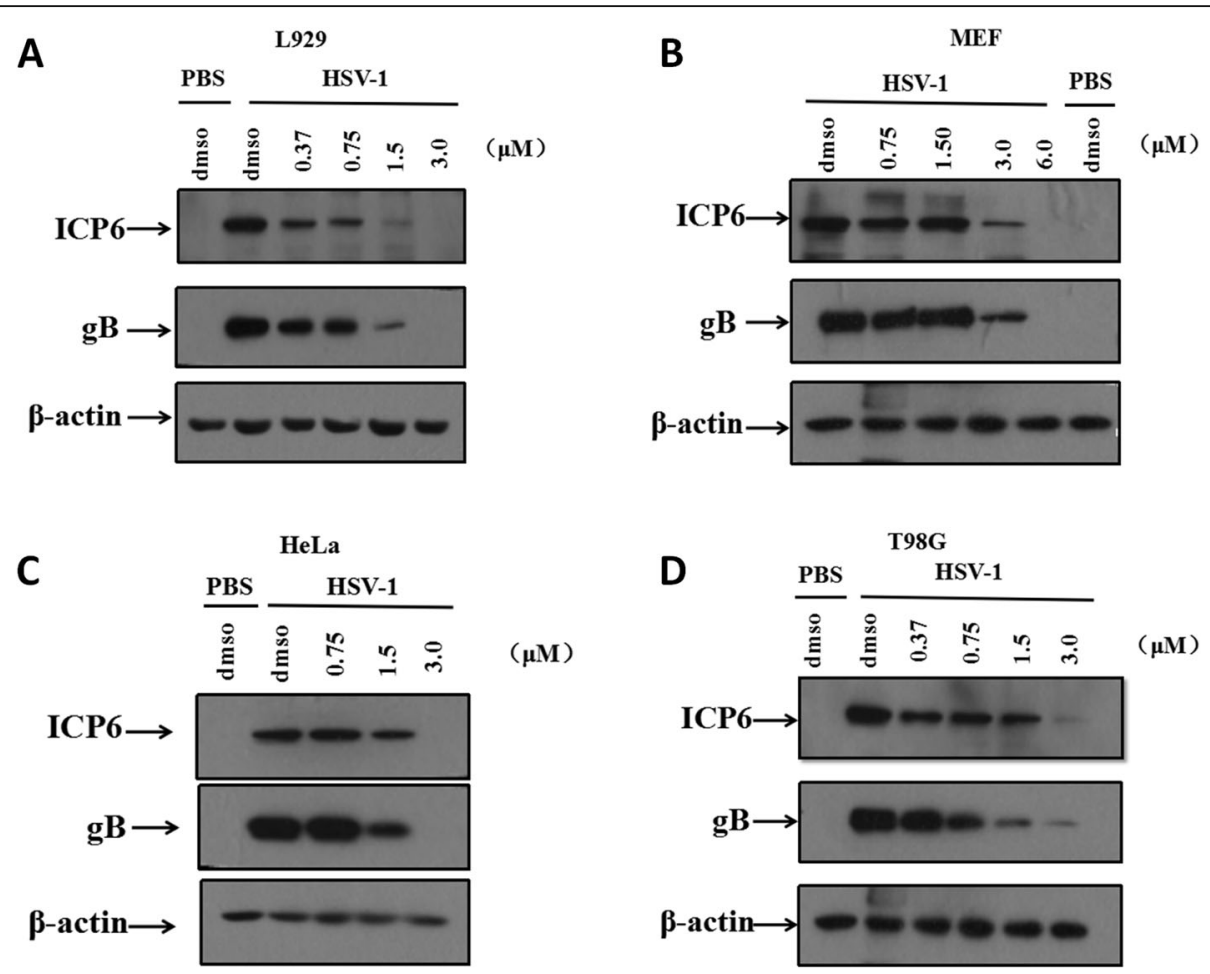

Fig. 2 MD significantly suppressed the expression levels of HSV-1 proteins. L929 (a), MEF(b), HeLa(c) and T98G(d) were pretreated with DMSO or MD at indicated concentration for $1 \mathrm{~h}$ prior to infection with HSV-1 for additional $6 \mathrm{~h}$. Viral proteins were harvested from cell lysates and the expression levels of $\mathrm{gB}$ and ICP6 were detected by western blot analysis

effect on the promoter activity of $I C P O$, which suggests that MD interfered with the transcription of viral immediate early genes without affecting the promoter activity of ICPO (Fig. 4d).

\section{MD has no effect on NF-KB or MAPK activation}

We proceeded to explore the molecular mechanism by which immediate early genes were inhibited by MD. It has been reported that efficient replication of HSV-1 relies on the activation of the NF- $\mathrm{kB}$ pathway in the host cell [30-32]. We further tested whether MD suppressed the expression of viral genes by disturbing the NF- $\mathrm{KB}$ pathway. Both viral evasion and antiviral cytokines such as TNF- $\alpha$ are able to induce activation of the NF- $\kappa B$ pathway, so we used recombinant protein TNF- $\alpha$ to trigger the pathway. As shown in Fig. 5a, MD did not abolish TNF- $\alpha$-induced phosphorylation of I $\mathrm{I} B \alpha$ and P65 (Fig. 5a). Using confocal microscopy, we found that MD did not block nuclear translocation of the P65 protein in response to TNF- $\alpha$ stimulation, which was consistent with the western blot results (Fig. 5b). Therefore, MD had no effect on the NF- $\mathrm{kB}$ signalling pathway. Moreover, the MAPK signalling pathway has also been reported to be involved in the regulation of cytokine production and viral replication [32-34], so we also investigated whether this pathway was affected by MD.
We found that MD showed no effect on the activation of ERK and AKT, which are critical components of the MAPK pathway (Fig. 5c, d). Thus, all these data show that MD exhibits anti-HSV-1 activity independent of the cellular NF-kB and MAPK pathways.

\section{Discussion}

HSV-1 is a highly contagious virus that establishes a lifelong latent infection in host cells. During the latent period, the virus infects sensory neurons near the site of primary infection, and the virions hide in the nucleus of the neuron. When the virus is reactivated by the proper stimulus, the virus initiates a lytic infection. HSV-1 infects the epithelium and initiates lytic replication, which further leads to cellular toxicity and tissue lesions. With the participation of cellular transcription factors, HSV-1 genes are transcribed by cellular RNA polymerase II in a highly regulated cascade. Once the viral genome invades the host nucleus, the immediate early genes, including ICP0 and ICP4, play an essential role in initiating viral transcription. Regulated by the immediate early genes, early genes are expressed approximately $2-8 \mathrm{~h}$ after infection. The products of early genes are involved in viral replication, while the products of late genes are usually structural proteins $[14,15]$. 


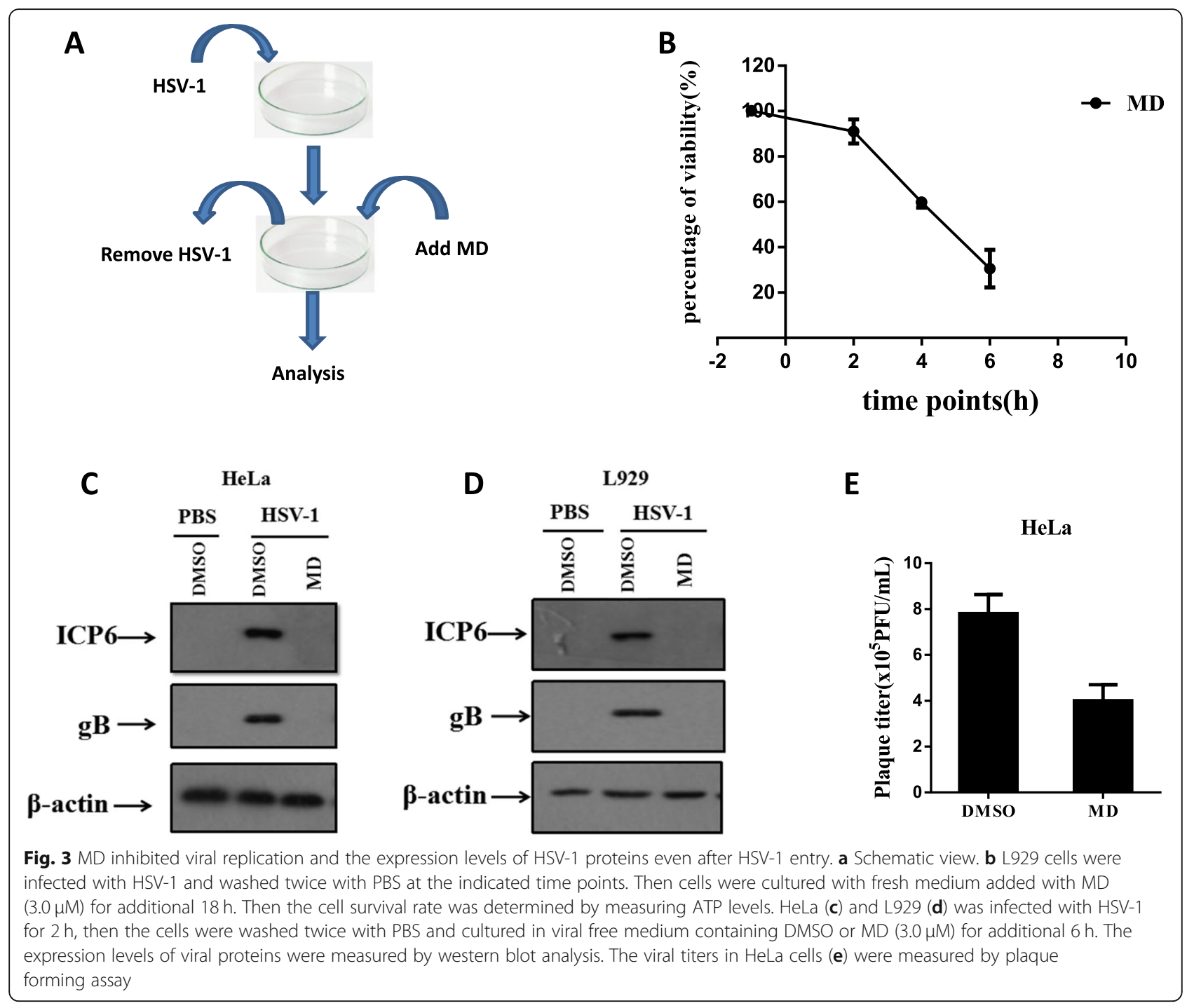

HSV-1 is a threat to human health and causes a number of diseases ranging from simple cold sores to keratitis and lethal encephalitis [5-9]. Current antiHSV-1 drugs including acyclovir, penciclovir and foscarnet are viral DNA synthesis inhibitors. Acyclovir and penciclovir are commonly used for the treatment of HSV-1 infection. Phosphorylated by virus-encoded thymidine kinases, acyclovir serves as a substrate for the virus DNA polymerase and prevents chain elongation and synthesis of the viral DNA. Penciclovir exerts antiviral activity by a similar mechanism as acyclovir [22, 23]. Foscarnet is a phosphonic acid derivative that inhibits HSV-1 replication by inhibiting the pyrophosphate site on the herpesvirus DNA polymerase [24]. However, with the chronic administration of anti-HSV drugs, drug-resistant HSV-1 strains have become a major threat worldwide. In particular, patients with immunodeficiencies are prone to develop drug-resistant HSV-1 strains. Considering that attempts to develop a vaccine against HSV-1 have been found to be ineffective, there is an urgent need to develop new effective antiviral drugs.

It has been reported that MD has antitumour effects, especially against lymphoma, breast cancer and prostate cancer, by targeting DNA topoisomerase II [25-27]. However, its anti-HSV-1 effect has not been reported. In our study, we found that MD suppressed HSV-1induced toxicity at $3.13 \mu \mathrm{M}$ and had no obvious cytotoxicity to cells at this concentration. Further experiments demonstrated that MD suppressed GFP-tagged HSV-1 replication and viral titers in host cells. We tested our hypothesis, that MD shows antiviral activity against HSV-1 by inhibiting the expression levels of viral proteins. We found that the expression levels of viral genes, including ICP6 and gB, were significantly suppressed by western blot analysis. Therefore, we found that MD blocked HSV-1-induced toxicity and suppressed viral protein synthesis. Given that MD can interact with topoisomerase II to regulate DNA synthesis, examination of 


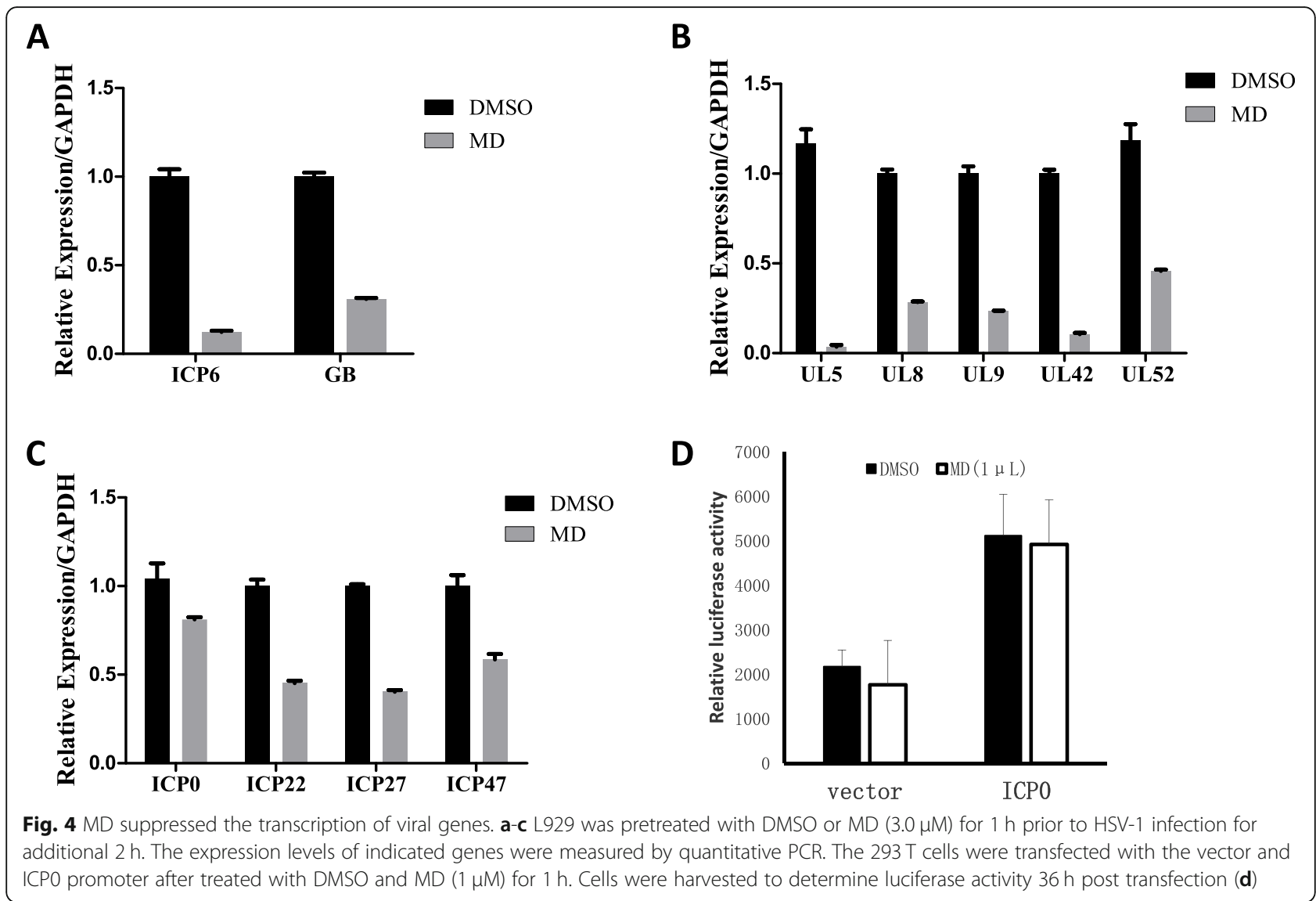

whether MD reduces the expression level of viral genes by directly binding topoisomerase II is a promising direction to evaluate the possible mechanism of antiviral efficacy of MD in the future.

Viral infection is a complex process consisting of virus entry into host cells, replication and transcription of the viral genome, viral protein synthesis, viral assembly, and release [35]. Antiviral medications act by impeding any of these steps. To elucidate whether MD protects cells from HSV-1 infection at viral entry or post viral entry, we changed the order in which HSV-1 and MD were added to cells. The results showed that MD still suppressed viral protein synthesis and viral titers in host cells even after the virus had entered the host cells. Therefore, MD showed antiviral efficacy mainly by suppressing viral protein synthesis rather than blocking the entry of viruses into host cells.

The transcription factor NF- $\mathrm{KB}$, a heterodimer of the P65 and P50 subunits, is involved in many cellular events, such as innate and adaptive immunity and inflammation. The efficient replication of HSV-1 relies on the activation of the NF- $\mathrm{KB}$ pathway in host cells. Moreover, it has been reported that the MAPK signalling pathway is also involved in the regulation of cytokine production and viral replication [32]. Therefore, we focused on whether MD inhibits HSV-1 replication by blocking the NF- $\mathrm{kB}$ and MAPK pathways. According to our results, the phosphorylation of IкB $\alpha$ and the nuclear translocation of the $\mathrm{P} 65$ protein were affected by MD treatment. In addition, we did not find that MD had any effect on the activation of the MAPK pathway. Therefore, MD exerts antiviral activity in a manner that is dependent on disturbing the activation of the NF- $\kappa B$ and MAPK pathways.

MD interrupted viral protein synthesis, so we also examined whether the transcription of viral genes was interrupted in the presence of MD. We found that the transcription of UL5, UL9, UL29, UL30, UL42 and UL52, all of which are necessary for viral DNA synthesis, was inhibited by MD. Moreover, the HSV-1 immediate early genes play important roles in regulating the expression of the early genes and late genes. Notably, we also found that the transcription of immediate early genes $I C P 0, I C P 22, I C P 27$, and ICP47, was also reduced in the presence of MD. Therefore, MD inhibits viral protein synthesis by interrupting the transcription of viral immediate early genes.

As one of the immediate early proteins, ICP0 has many biological functions. Some studies found that HSV-1 ICP0 mutant viruses might yield avirulent 


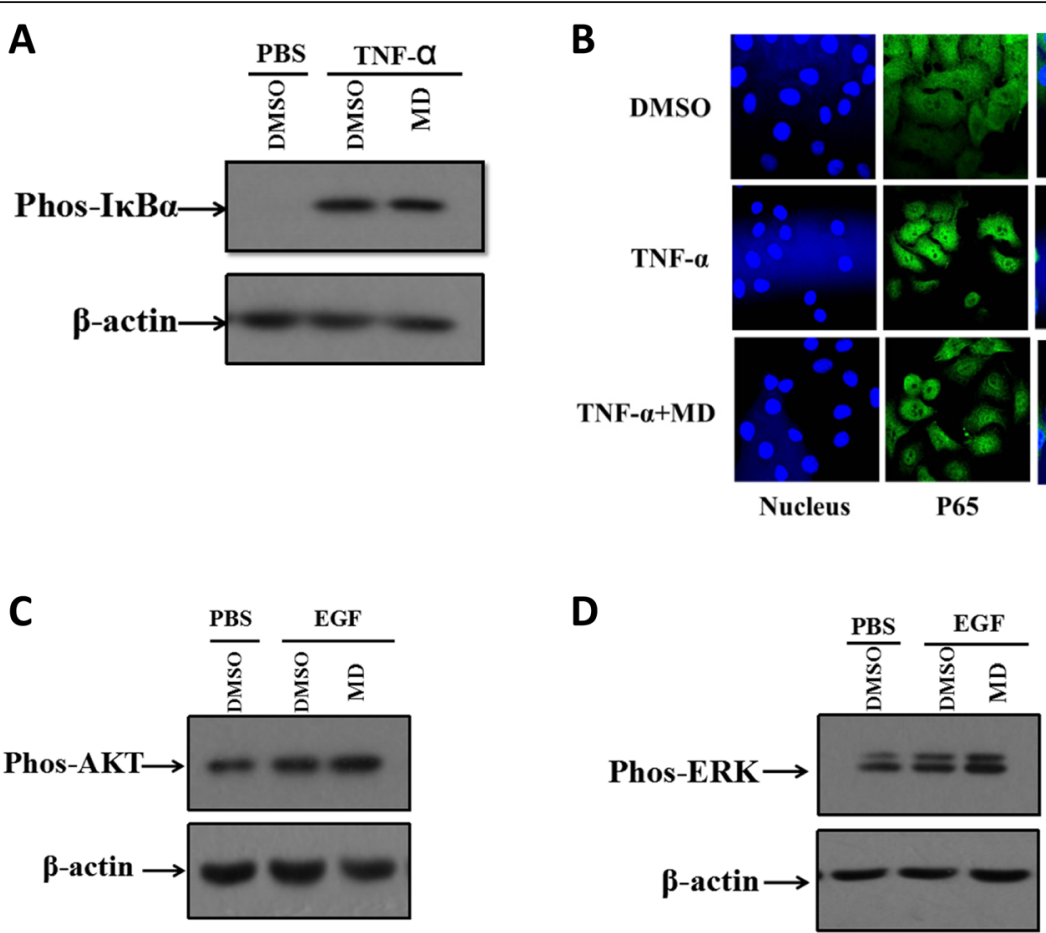

Fig. 5 The activations of NF-KB and MAPK signaling pathways and ICPO promotor activity were not affected by MD. a HeLa were pretreated with DMSO or MD $(3.0 \mu \mathrm{M})$ for $1 \mathrm{~h}$ prior to stimulation with TNF-a $(100 \mathrm{ng} / \mathrm{mL})$ for $15 \mathrm{~min}$. Then some of the HeLa cells were subjected to western blot to analyze the occurrence of IkBa phosphorylation. The rest of HeLa cells were stained with anti-P65 antibody (green) and DAPI (blue). The pictures were captured by confocal laser scanning microscope. b RD cells were cultured in serum free medium for $5 \mathrm{~h}$. Then cells were treated with DMSO or MD $(3.0 \mu \mathrm{M})$ and cultured in serum free medium for additional $1 \mathrm{~h}$. EGF was added for $15 \mathrm{~min}$ to stimulate activation of MAPK pathway. The occurrence of AKT (c) and ERK (d) phosphorylation were analyzed by western blot analysis

progeny, suggesting that ICP0 plays a pivotal role during lytic and latent infection [36, 37]. However, according to our results, MD had no effect on the promoter activity of ICPO, which suggests that MD interrupts the transcription of viral immediate early genes without affecting the promoter activity of ICPO. It is still an interesting future direction to examine the promoter activities of other immediate early genes to explore the precise molecular mechanism of action of MD against HSV-1.

\section{Conclusions}

In conclusion, mitoxantrone dihydrochloride is an interesting candidate for the development of a novel therapeutic drug against HSV-1 infectious disease that relies on its effective anti-HSV-1 activity.

\section{Methods}

\section{Antibodies and reagents}

The following antibodies were used for Westernblotting: $\beta$-actin (A2066; Sigma), gB (6506; Abcam), pERK (4370; cell signaling) and p-IкB $\alpha$ (9246; Cell Signaling). Mitoxantrone dihydrochloride was purchased from sigma (M6545). HSV-1 ICP6 polyclonal antibody was generated against the N-terminal peptide of ICP6. TNF- $\alpha$ recombinant protein was generated according to previously instruction [38].

\section{Cells and viruses}

Mouse fibroblast cells (L929) and African green monkey kidney cells (Vero) in which the viruses were propagated was from ATCC (American Type Culture Collection). Mouse embryonic fibroblasts (MEFs) were isolated from day 14.5-15.5 embryos. HSV-1 KOS strain was kindly provided by Dr. Sandra K. Weller (University of Conecticut Health Center) and GFP-labeled HSV-1 F stain was kindly provided by Dr. Chunfu Zheng (Soochow University).

\section{Cell survival}

Cell Titer-Glo Luminescent Cell Viability Assay kit (Promega) was used to determine cell survival by measuring ATP levels according to the manufacturer's instruction.

\section{Plaque forming assay}

The infection of cells was performed at an MOI of 2 for $6 \mathrm{~h}$. The harvested cells were frozen and thawed three times and then spun down at $13000 \mathrm{x}$ g for $5 \mathrm{~min}$. The supernatant containing virus was collected to infect cells 
for $12 \mathrm{~h}$. The cells then were stained with crystal violet solution (2\%) Then by using the Inverted microscope, the viral plaque formation were counted.

\section{Western blot analysis}

Cell pellet was collected by centrifugation at $13000 \mathrm{x} \mathrm{g}$ for $1 \mathrm{~min}$. The harvested cells were washed once with PBS and then resuspended in lysis buffer consist of $20 \mathrm{mM}$ Tris-HCl, PH 7.4, $150 \mathrm{mM} \mathrm{NaCl}, 10 \%$ glycerol, $1 \%$ Triton $\mathrm{X}-100,1 \mathrm{mM}$ Na3VO4, 25mM $\beta$-glycerolphosphate, 0.1 mM PMSF, a complete protease inhibitor set (Roche). The resuspended cell pellet was vortexed for 20s. lysis on ice for $20 \mathrm{~min}$ before cell lysates were centrifuged at $13000 \mathrm{x}$ g for $20 \mathrm{~min}$ at $4{ }^{\circ} \mathrm{C}$. The supernatants which the soluble proteins are in were collected and subjected to western blot analysis. The proteins were detected by using appropriate antibody.

\section{Determination of viral RNA levels}

Viral total RNA for real-time PCR was extracted by using TRIzol isolation (Invitrogen). Reverse transcription reactions were performed with reverse transcriptase (Life technology). Levels of various genes were finally analyzed by real-time PCR. The real-time was performed using specific primers for the ICP6, ICP0, ICP22, ICP27, ICP47, UL5, UL8, UL9, UL42, UL52. The sequence of primers used for Q-PCR analysis is shown in Additional file 1: Table S1.

\section{Cell infected with GFP-labeled virus imaging}

HeLa cells were seeded into the 6-well plates at a density of $3 \times 10^{6}$ and were infected with GFP-labeled HSV$1(\mathrm{MOI}=2)$ for $8 \mathrm{~h}$. Cells were analyzed for GFP by Leica DMILLED inverted microscope.

\section{Transfection and luciferase reporter assay}

The $293 \mathrm{~T}$ were pretreated with DMSO and MD $(1 \mu \mathrm{M})$ for $1 \mathrm{~h}$. Then the $293 \mathrm{~T}$ cells were co-transfected with pGL4.17 containing the ICP0 promotor sequence and RLTK plasmids by using lipofectamine 2000 reagent (Invitrogen). Cells were harvested to determine luciferase activity $36 \mathrm{~h}$ post transfection using the Dual-Luciferase Reporter Assay System kit (Promega, WI, USA, E1980) by a luminometer instrument.

\section{Immunofluorescence technique}

HeLa cells were seeded on glass coverslips at a density of $3 \times 10^{4}$ cells/plate and cultured overnight. The cells were pretreated with DMSO or MD for $1 \mathrm{~h}$. Then, the cells were washed twice with PBS after treatment with TNF- $\alpha(100 \mathrm{ng} / \mathrm{mL})$ for about $15 \mathrm{~min}$. Fix the cultured cells for $15 \mathrm{~min}$ with $4 \%$ paraformalde-hyde and Permeate the cells at room temperature for $15 \mathrm{~min}$ with $0.5 \%$ Triton X-100. Cells were blocked with $5 \%$ bovine serum albumin (BSA) in
PBS for $30 \mathrm{~min}$, then the primary antibody and secondary antibody was added successively. Nuclear was stained with DAPI. Image were observed and collected under a confocal laser scanning microscope.

\section{Statistical analyses}

Data of cell-survival rate are represented as the mean \pm SD of duplicates. All experiments were repeated at least three times with similar results. Significance was evaluated using $\mathrm{t}$ tests (GraphPad Prism software).

\section{Additional file}

Additional file 1. List of PCR primers used in Q-PCR assay.

\section{Abbreviations}

HSV-1: Herpes simplex virus-1; MD: Mitoxantrone dihydrochloride; NFKB: Nuclear Factor-kB; TNF-a: Tumor necrosis factor- $a$

\section{Acknowledgements}

We would like to express our gratitude to the professor Sudan He for experimental design and data analysis. The abstract of this work has previously been presented at the 28th Regional Congress of the ISBT as a poster (Guangzhou, China, November 25-28, 2017).

\section{Authors' contributions}

$\mathrm{HQ}$ and $\mathrm{HJ}$ contributed equally to this study. $\mathrm{HQ}, \mathrm{HJ}, \mathrm{CXH}, \mathrm{YJ}, \mathrm{YX}$ and YP carried out the experiments. The manuscript draft was written by $\mathrm{HQ}$ and $\mathrm{HJ}$ and was revised by HJ. All authors read and approved the final manuscript.

\section{Funding}

This work was supported by the National Natural Science Foundation of China [81701213]. None of the funding bodies was involved in the design of the study, the collection, analysis, or interpretation of data, or in writing the manuscript.

\section{Availability of data and materials}

All data generated or analyzed during this study are included in this published article.

Ethics approval and consent to participate

Not applicable.

Consent for publication

Not applicable.

\section{Competing interests}

The authors declare that they have no competing interests.

\section{Author details}

${ }^{1}$ Department of Obstetrics and Gynecology, Suzhou Dushuhu Public Hospital (Soochow University Multi-Disciplinary Polyclinic), Suzhou, China. ${ }^{2}$ Blood Research Laboratory, Chengdu Blood Center, Chengdu, Sichuan 610041, China. ${ }^{3}$ Cyrus Tang Hematology Center, Collaborative Innovation Center of Hematology, Jiangsu Institute of Hematology, the First Affiliated Hospital, Jiangsu Key Laboratory of Preventive and Translational Medicine for Geriatric Diseases, Soochow University, Suzhou, China. ${ }^{4}$ Department of emergency medicine, First Affiliated Hospital, Soochow University, 1 Shizi Rd, Suzhou, China. ${ }^{5}$ Department of Pulmonology, First Affiliated Hospital, Soochow University, Suzhou, China. 
Received: 18 April 2019 Accepted: 12 November 2019

Published online: 07 December 2019

\section{References}

1. Bzik DJ, Fox BA, DeLuca NA, Person S. Nucleotide sequence specifying the glycoprotein gene, $\mathrm{gB}$, of herpes simplex virus type 1. Virology. 1984:133(2):301-14

2. Smith JS, Robinson NJ. Age-specific prevalence of infection with herpes simplex virus types 2 and 1: a global review. J Infect Dis. 2002; 186(Suppl 1):S3-28s

3. Gamus D, Romano A. Herpetic imprint on privileged areas of its target organs: local latency and reactivation in herpetic keratitis. Metab Pediatr Syst Ophthalmol. 1988;11(1):37-40.

4. Knotts FB, Cook ML, Stevens JG. Latent herpes simplex virus in the central nervous system of rabbits and mice. J Exp Med. 1973;138(3):740-4.

5. Delmonte S, Sidoti F, Ribero S, Dal Conte I, Curtoni A, Ciccarese G, Stroppiana E, Stella ML, Costa C, Cavallo R, et al. Recurrent herpes labialis and HSV-1 herpes genitalis: which is the link? G Ital Dermatol Venereol. 2019;154(5):529-32.

6. Dolin R, Gill FA, Nahmias AJ. Genital herpes simplex virus type 1 infection-variability in modes of spread. J Am Vener Dis Assoc. 1975;2(2):13-6.

7. Hamroush A, Welch J. Herpes simplex epithelial keratitis associated with daily disposable contact lens wear. Cont Lens Anterior Eye. 2014;37(3):228-9.

8. Rowe AM, St Leger AJ, Jeon S, Dhaliwal DK, Knickelbein JE, Hendricks RL. Herpes keratitis. Prog Retin Eye Res. 2013;32:88-101.

9. Rabinstein AA. Herpes virus encephalitis in adults: current knowledge and old myths. Neurol Clin. 2017:35(4):695-705.

10. Farooq AV, Valyi-Nagy T, Shukla D. Mediators and mechanisms of herpes simplex virus entry into ocular cells. Curr Eye Res. 2010;35(6):445-50.

11. Turner A, Bruun B, Minson T, Browne H. Glycoproteins gB, gD, and gHgL of herpes simplex virus type 1 are necessary and sufficient to mediate membrane fusion in a Cos cell transfection system. J Virol. 1998;72(1):873-5.

12. Lacasse JJ, Schang LM. During lytic infections, herpes simplex virus type 1 DNA is in complexes with the properties of unstable nucleosomes. J Virol. 2010;84(4): 1920-33.

13. Preston $\mathrm{CM}$. Repression of viral transcription during herpes simplex virus latency. J Gen Virol. 2000;81(Pt 1):1-19.

14. Honess RW, Roizman B. Regulation of herpesvirus macromolecular synthesis: sequential transition of polypeptide synthesis requires functional viral polypeptides. Proc Natl Acad Sci U S A. 1975;72(4):1276-80.

15. Honess RW, Roizman B. Regulation of herpesvirus macromolecular synthesis. I. Cascade regulation of the synthesis of three groups of viral proteins. J Virol. 1974;14(1):8-19.

16. Watson R, Clements JB. A herpes simplex virus type 1 function continuously required for early and late virus RNA synthesis. Nature. 1980;285(5763):329-30.

17. Everett $\mathrm{RD}$. ICPO, a regulator of herpes simplex virus during lytic and latent infection. Bioessays. 2000;22(8):761-70.

18. Uprichard SL, Knipe DM. Herpes simplex ICP27 mutant viruses exhibit reduced expression of specific DNA replication genes. J Virol. 1996;70(3): 1969-80.

19. Crute JJ, Mocarski ES, Lehman IR. A DNA helicase induced by herpes simplex virus type 1. Nucleic Acids Res. 1988;16(14A):6585-96.

20. Crute JJ, Tsurumi T, Zhu LA, Weller SK, Olivo PD, Challberg MD, Mocarski ES, Lehman IR. Herpes simplex virus 1 helicase-primase: a complex of three herpes-encoded gene products. Proc Natl Acad Sci U S A. 1989;86(7):2186-9.

21. Weller SK, Coen DM. Herpes simplex viruses: mechanisms of DNA replication. Cold Spring Harb Perspect Biol. 2012;4(9):a013011.

22. Wade JC, Newton B, Flournoy N, Meyers JD. Oral acyclovir for prevention of herpes simplex virus reactivation after marrow transplantation. Ann Intern Med. 1984;100(6):823-8.

23. Saral R, Burns WH, Laskin OL, Santos GW, Lietman PS. Acyclovir prophylaxis of herpes-simplex-virus infections. N Engl J Med. 1981;305(2):63-7.

24. Earnshaw DL, Bacon TH, Darlison SJ, Edmonds K, Perkins RM, Vere Hodge RA. Mode of antiviral action of penciclovir in MRC-5 cells infected with herpes simplex virus type 1 (HSV-1), HSV-2, and varicella-zoster virus. Antimicrob Agents Chemother. 1992;36(12):274757.

25. Wang SL, Lee JJ, Liao AT. Comparison of efficacy and toxicity of doxorubicin and mitoxantrone in combination chemotherapy for canine lymphoma. Can Vet J. 2016;57(3):271-6.
26. Komeili-Movahhed T, Fouladdel S, Barzegar E, Atashpour S, Hossein Ghahreman M, Nasser Ostad S, Madjd Z, Azizi E. PI3K/Akt inhibition and down-regulation of $\mathrm{BCRP}$ re-sensitize MCF7 breast cancer cell line to mitoxantrone chemotherapy. Iran J Basic Med Sci. 2015;18(5):472-7.

27. Hou L, Feng Q, Wang Y, Yang X, Ren J, Shi Y, Shan X, Yuan Y, Wang $Y$, Zhang $Z$. Multifunctional hyaluronic acid modified graphene oxide loaded with mitoxantrone for overcoming drug resistance in cancer. Nanotechnology. 2016;27(1):015701.

28. Hou J, Zhang Z, Qiang H, Yan J, Zhang X, Yu X, Tan G, Zheng C, Feng X, He S. Antiviral activity of PHA767491 against human herpes simplex virus in vitro and in vivo. BMC Infect Dis. 2017;17(1):217.

29. Salvucci LA, Bonneau RH, Tevethia SS. Polymorphism within the herpes simplex virus (HSV) ribonucleotide reductase large subunit (ICP6) confers type specificity for recognition by HSV type 1-specific cytotoxic T lymphocytes. J Virol. 1995;69(2):1122-31.

30. Teresa Sciortino M, Antonietta Medici M, Marino-Merlo F, Zaccaria D, Giuffrè M, Venuti A, Grelli S, Mastino A. Signaling pathway used by HSV-1 to induce NF-kB activation. Ann N Y Acad Sci. 2010;1096(1):89-96.

31. Hiscott J, Kwon H, Génin P. Hostile takeovers: viral appropriation of the NFkappaB pathway. J Clin Investig. 2001;107(2):143.

32. Goswami D, Mahapatra AD, Banerjee S, Kar A, Ojha D, Mukherjee PK, Chattopadhyay D. Boswellia serrata oleo-gum-resin and beta-boswellic acid inhibits HSV-1 infection in vitro through modulation of NF-small ka, CyrillicB and p38 MAP kinase signaling. Phytomedicine. 2018;51:94-103.

33. Gillis PA, Okagaki LH, Rice SA. Herpes simplex virus type 1 ICP27 induces p38 mitogen-activated protein kinase signaling and apoptosis in HeLa cells. J Virol. 2009;83(4):1767.

34. Chen D, Su A, Fu Y, Wang X, Lv X, Xu W, Xu S, Wang H, Wu Z. Harmine blocks herpes simplex virus infection through downregulating cellular NFKB and MAPK pathways induced by oxidative stress. Antivir Res. 2015;123:27.

35. Bedadala GR, Palem JR, Graham L, Hill JM, Mcferrin HE, Hsia SC. Lytic HSV-1 infection induces the multifunctional transcription factor early growth Response-1 (EGR-1) in rabbit corneal cells. Virol J. 2011:8(1):1-9.

36. Zhang J, Wang K, Wang S, Zheng C. Herpes simplex virus 1 E3 ubiquitin ligase ICP0 protein inhibits tumor necrosis factor alpha-induced NF-KB activation by interacting with p65/RelA and p50/NF-kB1. J Virol. 2013;87(23): 12935-48.

37. Liu M, Schmidt EE, Halford WP. ICPO dismantles microtubule networks in herpes simplex virus-infected cells. PLoS One. 2010;5(6):e10975.

38. He S, Wang L, Miao L, Wang T, Du F, Zhao L, Wang X. Receptor interacting protein kinase-3 determines cellular necrotic response to TNF-alpha. Cell. 2009:137:1100-11.

\section{Publisher's Note}

Springer Nature remains neutral with regard to jurisdictional claims in published maps and institutional affiliations.

\section{Ready to submit your research? Choose BMC and benefit from:}

- fast, convenient online submission

- thorough peer review by experienced researchers in your field

- rapid publication on acceptance

- support for research data, including large and complex data types

- gold Open Access which fosters wider collaboration and increased citations

- maximum visibility for your research: over $100 \mathrm{M}$ website views per year

At BMC, research is always in progress.

Learn more biomedcentral.com/submissions 